\title{
Stable hemoglobin in hemodialysis patients: forest for the trees - a 12-week pilot observational study
}

\author{
Jacques B Rottembourg ${ }^{1 *}$, Floride Kpade ${ }^{1}$, Fadia Tebibel ${ }^{1}$, Aurélie Dansaert ${ }^{1}$ and Gaelle Chenuc $^{2}$
}

\begin{abstract}
Background: Hemoglobin $(\mathrm{Hb})$ variability is a common occurrence in hemodialysis patients treated with erythropoiesis-stimulating agents. High amplitude fluctuations have been associated with greater risk of morbidity and mortality.

Methods: This prospective, single centre pilot observational study was conducted over a 3-month period in daily practice patterns, to assess per-dialysis events and inter-dialysis complications that could interfere with erythropoiesis in patients undergoing hemodialysis.

Results: Mean Hb levels remained stable in the 78 evaluable patients, as did darbepoetin alfa (DA) doses, including in patients suffering from diabetes or cardiac affections. In total, an average of 7.7 events / patient / month occurred, but no significant relationship with $\mathrm{Hb}$ excursions was shown.

Conclusion: The observation of 7.7 events per patient per month suggests a careful monitoring of $\mathrm{Hb}$ and DA dosing every other week, in order to maintain $\mathrm{Hb}$ level within the target.
\end{abstract}

Keywords: Darbepoetin alfa, Hemodialysis, Hemoglobin cycling, Inter-dialysis complications, Per-dialysis events

\section{Background}

Anemia is an important and common complication in patients with end-stage renal disease treated with chronic maintenance hemodialysis (HD). Its impact on cardiovascular outcomes, quality of life and even survival has been widely assessed. As a result, throughout the years, several guidelines have defined the targets in hemoglobin $(\mathrm{Hb})$ levels that need to be achieved in HD patients [1-5]. These have been recently modified by the KDIGO clinical practice guidelines for anemia in chronic kidney disease (CKD) [6]. Treatment with erythropoietin stimulating agents (ESAs) has been a major advance in the management of this problem. There is, however, a great difference between treatment and physiological erythropoietic biology, in so far as ESAs are administered episodically, generating important changes in erythropoietin - and hence - Hb levels [7]. This phenomenon,

\footnotetext{
* Correspondence: jacques.rottembourg@wanadoo.fr

'Dialysis Unit, Diaverum Group, Clinique Mont Louis, 11, passage Courtois,

75011, Paris, France

Full list of author information is available at the end of the article
}

which is commonly encountered in ESA-treated patients $[8,9]$, is known as Hb cycling. It can be defined as cyclical increases and decreases of measured $\mathrm{Hb}$ levels in individual patients [7]. Its consequences are not fully known, however it may be accepted that $\mathrm{Hb}$ cycling can result in fluctuations of the oxygen carried to the tissues, and repeated episodes of relative ischemia in vital organs can lead to organ dysfunction or injury. Indeed, high amplitude swings have been found to be associated with greater risk of mortality and hospitalization [10].

Apart from anemia management, several factors can be accounted for causing $\mathrm{Hb}$ cycling: amongst others, inflammatory and infectious diseases, blood loss, hyperparathyroidism and hospitalizations [7-9]. On the other hand, little is known about dialysis-related incidents, whether they occur during or between HD sessions.

This prospective, single-center pilot observational study was conducted over a 3-month period, to assess the number and importance of per-dialysis events and inter-dialysis complications that could possibly interfere with erythropoiesis in patients undergoing hemodialysis.

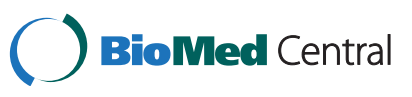




\section{Methods}

Patients were treated according to routine clinical practices in the unit. As required by law, no formal approval was required by the independent ethic committee, and patients provided written informed consent prior to study entry [11]. All patients treated in our center were included for 12 weeks in the study. They were prescribed regular HD on Integra-Hospal generators for 3.5 to 4 hours three times weekly. Vascular access was assessed by double arterio-venous fistula punctures in all patients. On start of the dialysis session, each patient received a 0.2 to $0.6 \mathrm{ml}$ injection of nadroparin calcium, a low molecular weight heparin. High and medium permeability membranes were used throughout the study and were unchanged for each patient. Darbepoetin alfa (DA) injections were performed every other week (during the first dialysis session of the week) in the venous injection site before the drip chamber on the venous line (Pivipol Hospal). Any change in the dosing of DA required a follow-up of four $\mathrm{Hb}$ measurements, and the adaptation was made by one physician who knows the previous doses and the clinical program of the patient: if, on $4 \mathrm{Hb}$ values, one was outside of the target, nothing was changed; if 2 or 3 values were outside of the target, the dosing was adapted depending the amplitude. Intravenous (IV) iron (iron sucrose [V]) was injected, if necessary, once a week during the second dialysis session at a dose ranging from 25 to $100 \mathrm{mg}$.

The follow-up conditions were those of daily practice, and the protocol ensured that no complementary visits or biological assessments would be performed outside the usual HD follow-up. Biological parameters such as $\mathrm{Hb}$, calcium, phosphorus, urea, creatinine and DA dose, were assessed every other week; iron dose was recorded every week. Other parameters, and especially C-reactive protein, PTH and nutritional parameters [albumin and normalized protein catabolic rate (nPCR)] were assessed at baseline and on week 12; dialysis adequacy was assessed at the same period by $\mathrm{Kt} / \mathrm{V}$ and urea reduction ratio (URR). $\mathrm{Hb}$ variation was defined as $\mathrm{a} \geq 1 \mathrm{~g} / \mathrm{dl} \mathrm{Hb}$ excursion above or under baseline value and $\mathrm{a} \geq 4$ weekduration.

Upon each dialysis session, per-dialysis events, such as fistula bleeding, puncture problems, hypotension, clotting in lines or dialyzer, blood loss, and delayed coagulation, were recorded by the nurses on specific questionnaires. Physicians assessed each week inter-dialysis complications, mainly cardiovascular, digestive, infectious, hemorrhagic, and vascular access, by three means of consultation: face to face, by phone, and, when in doubt, by consulting the family.

Descriptive statistics were applied for quantitative variables, and results are reported with mean values and standard deviations; median values and ranges are also provided when appropriate, owing to dispersion of values. A uni-variate analysis was performed to assess if there is an association between events (per-dialysis and inter-dialysis) and hemoglobin excursion. The evaluable population comprised patients who attended every dialysis session during this prospective study; patients who were absent for any reason (vacation, prolonged hospitalization, graft, death) were excluded.

\section{Results}

\section{Evaluable population}

Out of 100 patients undergoing HD in the center, 78 attended every dialysis session for 3 months, and therefore constituted the evaluable population. 22 patients were excluded because they did not attend all the dialysis sessions: 2 patients died, 4 were grafted, 7 were hospitalized for 3 to 28 days, and 9 went in vacation. The demographics and characteristics of these 78 patients, at baseline, were shown in Table 1. More than two-thirds were males, and the mean $( \pm$ SD) age was $59( \pm 16.6)$ years. They had been undergoing dialysis for a median time of almost three years (34.5 months). Nearly all of them (94.9\%) suffered from hypertension, and $47.4 \%$ from cardiac insufficiency. Medical history and current treatments at baseline are shown in Table 2.

\section{Hemoglobin and DA dose, iron dose}

Over the study period, mean $\mathrm{Hb}$ levels remained stable in the evaluable population, as did DA doses (Table 3). Throughout the study, approximately $80 \%$ of patients had levels $\geq 11 \mathrm{~g} / \mathrm{dl}$. Similar findings were reported for patients suffering from cardiac affections or from

\section{Table 1 Demographics and characteristics at baseline}

\begin{tabular}{ll}
\hline Characteristics & $\begin{array}{l}\text { Evaluable patients } \\
(\mathbf{n}=\mathbf{7 8})\end{array}$ \\
\hline Gender, $\mathbf{n}(\%)$ & $54(69.2)$ \\
$\quad$ Male & $24(30.8)$ \\
$\quad$ Female & \\
Age (years) & $59.0(16.6)$ \\
$\quad$ Mean (SD) & \\
BMI (kg/m ${ }^{2}$ ) & $22.6(4.3)$ \\
$\quad$ Mean (SD) & \\
Primary cause of renal failure, $\mathbf{n}(\%)$ & $16(20.5)$ \\
Diabetes & $10(12.8)$ \\
Hypertension & $24(30.8)$ \\
Glomerulonephritis & $28(35.9)$ \\
Other & \\
Dialysis vintage (months) & \\
Mean (SD) & $49.6(47.1)$ \\
Median (range) & $34.5(2.0-293.0)$ \\
\hline
\end{tabular}




\begin{tabular}{ll}
$\begin{array}{l}\text { Table } \mathbf{2} \text { Current history and medical treatments at } \\
\text { baseline }\end{array}$ & Evaluable patients ( $\mathbf{n} \mathbf{7 8})$ \\
\hline Characteristics & $74(94.9)$ \\
\hline Medical History, $\mathbf{n}(\%)$ & $37(47.4)$ \\
Hypertension & $6(16.2)$ \\
Cardiac insufficiency & $25(67.6)$ \\
$\quad$ NYHA II & $6(16.2)$ \\
NYHA III & $22(28.2)$ \\
$\quad$ NYHA IV & $5(6.4)$ \\
Coronary artery disease & $7(9.0)$ \\
Myocardial infarction & $27(35.5)$ \\
Stroke & $20(25.6)$ \\
Limb arteritis & $10(12.8)$ \\
Hepatitis & \\
Cancer & $23(29.5)$ \\
Current treatments, $\mathbf{n}$ (\%) & $37(47.4)$ \\
ACE inhibitors and/or ARBs & $61(78.2)$ \\
VKAs, aspirin, platelet aggregation inh. & $7(9.0)$ \\
Dyslipidemia treatment & $17(21.8)$ \\
Hepatitis treatment &
\end{tabular}

NYHA: New York Heart Association; ACE: angiotensin converting enzyme; ARBs: angiotensin receptor blockers; VKAs: vitamin $\mathrm{K}$ antagonists.

diabetes (Table 4). A vast majority of patients required very few, if any, changes in DA doses during the 3months duration of the study: $46 \%$ of patients did not require any change, whilst $42 \%$ only required one change (Figure 1). Twelve patients require more than one adaptation of DA doses during the study: these patients are the one who suffered of the most events. Seven patients did not receive any DA treatment; as a whole, their $\mathrm{Hb}$ levels were slightly higher than those of the patients receiving DA: median $\mathrm{Hb}$ was $12.0 \mathrm{~g} / \mathrm{dl}$ at baseline, and remained stable over the 3-month period, even rising to a median of $13.2 \mathrm{~g} / \mathrm{dl}$ in the last two weeks. Sixty eight patients received IV iron at a mean $( \pm$ SD) dosage of 59 ( \pm 35$)$ mg per week.

\section{Biological variables}

Iron status remained stable throughout the study (Table 5). Serum ferritin was $\geq 100 \mu \mathrm{g} / \mathrm{l}$ in almost $95 \%$ of patients, both at baseline, and at the end of the study. Creactive protein at baseline, week 6 and week 12 was < $10 \mathrm{mg} / \mathrm{l}$ in a majority of patients $(76.2 \%, 84.5 .0 \%$ and $89.8 \%$ respectively). During the 3-month study period, nutritional variables also remained stable in the evaluable population (Table 5), as well as in cardiac and diabetic subgroups. Dialysis adequacy was achieved with a mean (SD) urea reduction ratio between $0.73(0.07)$ at baseline and $0.70(0.07)$ at the end of the study and $\mathrm{Kt} / \mathrm{V}$ at $1.49(0.39)$ and $1.35(0.34)$ respectively. Serum calcium, phosphorus and PTH were maintained in the current guidelines.

\section{Per-dialysis events and inter-dialysis complications}

Intercurrent events over the study duration, i.e. 2,808 dialysis sessions, are summarized in Table 6. As expected, most per-dialysis events were related to blood circuit, and almost all patients experienced at least once clotting (97.4\%) or blood loss and delayed coagulation (93.6\%). Hypotensive episodes occurred at least once in $84.6 \%$ of patients. Events related to HD technique, such as puncture problems and fistula bleeding, occurred less frequently with a total of 149 and 38 respectively, and concerned one half and one third of patients respectively.

Vascular access complications were also less frequent, occurring in $21.8 \%$ of patients. The most frequent interdialysis complications were digestive (76 experienced by $59 \%$ of patients), and infectious (83 experienced by $57.7 \%)$. There were no relationship between hemoglobin excursions and intercurrent events (Table 7).

Table 3 Hemoglobin concentrations and DA doses over time - Evaluable population $(\mathbf{n}=78)$

\begin{tabular}{|c|c|c|c|c|c|c|c|}
\hline Variables & Baseline & W2 & W4 & W6 & W8 & W10 & W12 \\
\hline \multicolumn{8}{|c|}{ Hemoglobin (g/dl) } \\
\hline Mean (SD) & $11.8(1.34)$ & $11.8(1.25)$ & $11.9(1.27)$ & $11.9(1.43)$ & $11.8(1.57)$ & $12.0(1.35)$ & $11.8(1.47)$ \\
\hline Median & 11.7 & 11.6 & 12.1 & 11.8 & 11.7 & 11.9 & 11.8 \\
\hline$\geq 11 \mathrm{~g} / \mathrm{dl}(\%)$ & 79.5 & 79.2 & 82.1 & 78.1 & 73.0 & 81.9 & 80.5 \\
\hline \multicolumn{8}{|c|}{ Weekly DA dose ( $\mu \mathrm{g} /$ week) } \\
\hline Mean (SD) & $47.7(40.2)$ & $45.9(40.8)$ & $45.6(40.8)$ & $43.2(39.6)$ & $42.7(39.3)$ & $42.2(39.6)$ & $40.9(38.5)$ \\
\hline Median & 30 & 30 & 30 & 30 & 30 & 30 & 30 \\
\hline \multirow{2}{*}{\multicolumn{8}{|c|}{$\begin{array}{l}\text { Weighted weekly DA dose } \\
(\mu \mathrm{g} / \text { week } / \mathrm{kg})\end{array}$}} \\
\hline & & & & & & & \\
\hline Mean (SD) & $0.76(0.7)$ & $0.75(0.8)$ & $0.74(0.8)$ & $0.70(0.7)$ & $0.70(0.7)$ & $0.70 .8)$ & $0.67(0.7)$ \\
\hline Median & 0.48 & 0.46 & 0.47 & 0.42 & 0.42 & 0.41 & 0.39 \\
\hline
\end{tabular}


Table 4 Hemoglobin concentrations and DA doses over time - Cardiac and diabetic patients

\begin{tabular}{|c|c|c|c|c|c|c|}
\hline \multirow[t]{2}{*}{ Variables } & \multicolumn{3}{|c|}{ Cardiac patients $(n=46)$} & \multicolumn{3}{|c|}{ Diabetic patients $(n=21)$} \\
\hline & Baseline & W6 & W12 & Baseline & W6 & W12 \\
\hline \multicolumn{7}{|c|}{ Hemoglobin (g/dl) } \\
\hline Mean (SD) & $11.9(1.5)$ & $12.1(1.5)$ & $11.7(1.7)$ & $12.0(0.7)$ & $11.9(0.8)$ & $11.7(1.0)$ \\
\hline Median (range) & $11.9(6.8-15.2)$ & $11.9(9.3-17.4)$ & $11.8(6.4-17.0)$ & $11.9(11.0-13.2)$ & $11.7(10.6-14.0)$ & $11.8(9.5-13.2)$ \\
\hline \multicolumn{7}{|l|}{ Weekly DA dose } \\
\hline \multicolumn{7}{|l|}{ ( $\mu \mathrm{g} /$ week) } \\
\hline Mean (SD) & $52.9(44.0)$ & $44.7(40.1)$ & $43.3(39.5)$ & $38.6(33.9)$ & $35.3(33.0)$ & $29.5(22.1)$ \\
\hline Median (range) & $40.0(10.0-200.0)$ & $30.0(10.0-200.0)$ & $30.0(10.0-200.0)$ & $30.0(10.0-150.0)$ & $25.0(10.0-150.0)$ & $20.0(10.0-100.0)$ \\
\hline \multirow{2}{*}{\multicolumn{7}{|c|}{$\begin{array}{l}\text { Weighted weekly DA dose } \\
(\mu \mathrm{g} / \text { week } / \mathrm{kg})\end{array}$}} \\
\hline & & & & & & \\
\hline Mean (SD) & $0.8(0.7)$ & $0.7(0.7)$ & $0.7(0.7)$ & $0.5(0.5)$ & $0.5(0.5)$ & $0.4(0.3)$ \\
\hline Median (range) & $0.53(0.2-3.3)$ & $0.43(0.2-3.3)$ & $0.45(0.1-3.3)$ & $0.38(0.2-2.4)$ & $0.38(0.2-2.4)$ & $0.36(0.1-1.5)$ \\
\hline
\end{tabular}

In total, an average of 7.7 events / patient / month occurred, that might interfere with erythropoiesis. There is no correlation between per-dialysis events and hemoglobin excursions $(\mathrm{r}=0.18, \mathrm{p}<0.52)$ and inter-dialysis events and hemoglobin excursions $(\mathrm{r}=0.21, \mathrm{p}<0.51)$.

\section{Discussion and conclusions}

Anemia, a common complication in patients with endstage renal disease on dialysis has been shown to increase the risk of morbidity and increased mortality, and alters quality of life. Ebben and colleagues studied 152,846 Medicare hemodialysis patients and defined six patients groups on the basis of hemoglobin level fluctuation [10]. The consistently low group $(\mathrm{Hb}<11 \mathrm{~g} / \mathrm{dl})$ had the highest percentage of hospitalizations and the highest number of co-morbid conditions. On the other hand, the CHOIR trial, in patients not on dialysis, showed that targeting a hemoglobin level of $13.5 \mathrm{~g} / \mathrm{dl}$ was associated with a significantly increased risk of a composite endpoint of death, myocardial infarction, hospitalization for congestive heart failure, and stroke,

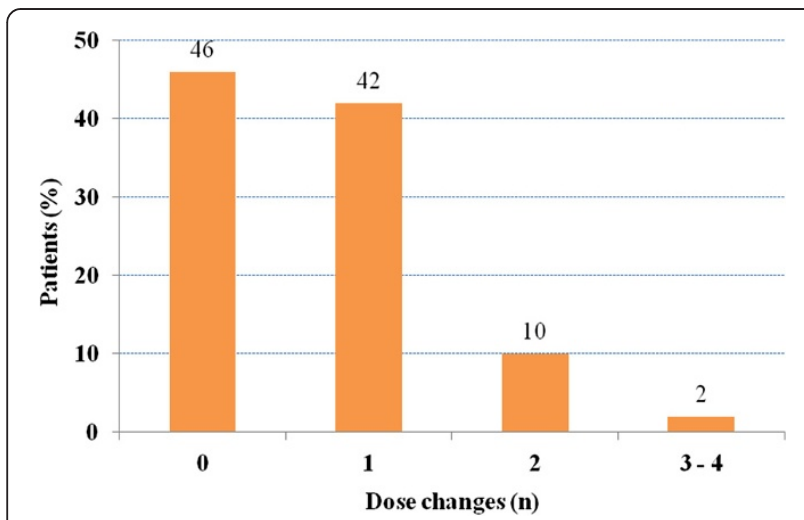

Figure 1 Proportions of patients requiring DA dose changes over time. without any significant improvement in quality of life [12]. A same figure was observed on hemodialysis in the Normal Hematocrit Study [13]. It appears that both low and high $\mathrm{Hb}$ levels are associated with increased mortality risk, in a U-shaped or inverse J-curve relationship [14]. Somewhat conflicting results have been published, however: in a 2-year duration study of 5,037 European $\mathrm{HD}$ patients, Eckard and colleagues determined $\mathrm{Hb}$ variability, and concluded that, although it is frequently seen in these patients, it does not independently predict mortality [15].

Table 5 Biological variables over time - Evaluable population $(\mathbf{n}=\mathbf{7 8})$

\begin{tabular}{lll}
\hline Variables & Baseline & Week 12 \\
\hline $\begin{array}{l}\text { Ferritin ( } \mathbf{\mu g} / \mathbf{l}) \\
\quad \text { Mean (SD) }\end{array}$ & $478(289.4)$ & $468(265.4)$ \\
$\quad$ Median & 456 & 443 \\
$\quad<100 \mu \mathrm{g} / \mathrm{l}, \mathrm{n}(\%)$ & $4(5.1)$ & $4(5.2)$ \\
Transferrin saturation (\%) & & \\
$\quad$ Mean (SD) & $40(9.2)$ & $41(8.9)$ \\
$\quad$ Median & 41 & 41 \\
Albumin (g/l) & & \\
$\quad$ Mean (SD) & $38.9(4.4)$ & $40.7(4.5)$ \\
$\quad$ Median & 38.7 & 40.7 \\
nPCR (g/kg/day) & & $0.8(0.2)$ \\
Mean (SD) & $0.9(0.2)$ & 0.8 \\
$\quad$ Median & 0.9 & $6.4(10.3)$ \\
C-reactive protein (mg/l), $\mathbf{n}(\%)$ & & $4.1(1.8),(89.9)$ \\
$\quad$ Mean (SD) & $9.8(13.5)$ & $29.8(25.0),(10.1)$ \\
$\quad<10$ mg/l, mean(SD), (\%) & $4.4(2.0),(76.4)$ & \\
$\geq 10$ mg/l, mean(SD), (\%) & $27.1(19.5),(23.6)$ & \\
\hline
\end{tabular}

nPCR: normalized protein catabolic rate. 
Table 6 Intercurrent events during the 3-month study

\begin{tabular}{lccc}
\hline Events & Total number of events & \% of patients with $\geq \mathbf{1}$ event & Mean number of events/patient/month \\
\hline Peridialysis events & 38 & 33.3 & 0.2 \\
$\quad$ Fistula bleeding & 149 & 50.0 & 0.6 \\
Puncture problem & 308 & 84.6 & 1.3 \\
Hypotension & 596 & 97.4 & 2.6 \\
Clotting (lines, dialyzer) & 425 & 93.6 & 1.8 \\
Blood loss \& delayed coagulation & & & 0.2 \\
Interdialysis complications & 48 & 34.6 & 0.3 \\
$\quad$ Cardiovascular & 76 & 59.0 & 0.4 \\
$\quad$ Digestive & 83 & 57.7 & 0.2 \\
Infectious & 52 & 41.0 & 0.1 \\
Hemorrhagic & 20 & 21.8 & \\
Vascular access & 52 & \\
\hline
\end{tabular}

The findings of our study support the hypothesis that patient-related factors such as per-dialysis events, interdialysis events and co-morbid conditions could influence the degree of $\mathrm{Hb}$ variability in patients undergoing $\mathrm{HD}$, if the monitoring of $\mathrm{Hb}$ and the dosing of $\mathrm{DA}$ are done with an interval exceeding two weeks. A total of 1516 per-dialysis events such as fistula bleeding, puncture problems, hypotension, clotting in the lines or dialyzer or delayed coagulation resulting in blood loss were observed along with 279 inter-dialysis events such as cardiovascular, infectious hemorrhagic and vascular access complications that did not lead to hospitalizations, or for no more than two days. This resulted in a mean 7.7 events per month per patient potentially interfering with erythropoiesis.

Defining an optimal level for $\mathrm{Hb}$ patients with CKD is therefore difficult. This may explain why guidelines have evolved during the past decade, recommending a target of 10 to12 $\mathrm{g} / \mathrm{dl}$ for the latest KDOQI guidelines [16,17], which is narrower for ERBP (11-12 g/dl) [18], and much higher than the new KDIGO (9.5-11.5 g/dl) [6].

A small number of HD patients, however, have normal $\mathrm{Hb}$ levels and have no need for ESAs. A population of

Table 7 Intercurrent events according to hemoglobin excursion

\begin{tabular}{lccc}
\hline & \multicolumn{3}{c}{ Hemoglobin excursion* } \\
\cline { 2 - 4 } & All & No & Yes \\
Events & $\mathbf{( N = 7 8 )}$ & $\mathbf{( N = 4 6 )}$ & $\mathbf{( N = 3 2 )}$ \\
\hline Cardiovascular complication & $27(34.6 \%)$ & $17(37 \%)$ & $10(31.3 \%)$ \\
Digestive tract complication & $46(59 \%)$ & $27(58.7 \%)$ & $19(59.4 \%)$ \\
Infectious complication & $45(57.7 \%)$ & $26(56.5 \%)$ & $19(59.4 \%)$ \\
Hemorrhagic complication & $32(41.0 \%)$ & $16(34.8 \%)$ & $16(50.0 \%)$ \\
Access complication & $17(21.8 \%)$ & $12(26.1 \%)$ & $5(15.6 \%)$ \\
\hline
\end{tabular}

*Hemoglobin excursion: variation $\geq 1 \mathrm{~g} / \mathrm{dl}$ in up or down and duration $\geq 4$ weeks.
45 non anemic HD patients was compared to a control group of $205 \mathrm{HD}$ patients on ESA therapy [19]. Absence of anemia was more frequent in men and younger patients with long-term renal replacement therapy, in patients with $\mathrm{HCV}+$ liver disease and adult polycystic kidney disease, associated with increased endogenous erythropoietin production and renal and hepatic cysts. In our study, 7 of the 78 evaluable patients did not receive any ESA therapy, 3 of them had a polycystic kidney disease, 3 were diabetics and one had a nephrosclerosis.

More than a set target level, however, fluctuations in $\mathrm{Hb}$ levels have been shown to be associated with comorbid situations. This frequent phenomenon, known as hemoglobin cycling, can be defined as fluctuations over time in measured $\mathrm{Hb}$ levels, increasing above or decreasing below the target and reversing direction [7]. Apparently stable mean $\mathrm{Hb}$ levels in an overall study population can hide the occurrence of intra-individual variability in many patients. In a retrospective data analysis of $281 \mathrm{HD}$ patients receiving ESAs, an occurrence of $\mathrm{Hb}$ cycling in $90 \%$ of patients has been reported [9]. Lacson and colleagues reported important fluctuations over time, with only $5 \%$ of ESRD patients in the target range during a 6-month period observation [20]. In another retrospective study, undertaken in the Netherlands, none of the 97 ESA-treated patients had $\mathrm{Hb}$ levels stable within the target range over a one-year period [21]. In our present study, we report stable levels of hemoglobin as a whole in the evaluable population, as well as in the cardiac and diabetic subgroups, during the whole study period. However $54 \%$ of the patients needed at least one change in darbepoetin alfa dose, to compensate $\mathrm{Hb}$ fluctuations outside the target level. In our unit, over the last few years, the median number of darbepoetin alfa dose changes per year is about three [22].

Numerous causes have been identified that can result in $\mathrm{Hb}$ cycling. Some are patient-related, such as age 
(older patients show smaller variability) [23], co-morbid conditions, e.g. inflammatory states or infections [10], levels of parathyroid hormone, and concurrent hematologic disorders. In HD patients, red blood cells have a short circulating half-life, due to fluctuations in erythropoietin levels, and this is a component of variability in $\mathrm{Hb}$ levels [24].

Other causes of $\mathrm{Hb}$ variability are drug-related: ESAs have been a major advance in anemia management, but also contribute to $\mathrm{Hb}$ cycling, and compounds pharmacokinetics, dosing and frequency of administration generate substantial changes in erythropoiesis [25-27]. For Portoles, long-acting ESA, darbepoetin alfa, achieved better $\mathrm{Hb}$ stability than short-acting ESA [28]. Iron homeostasis also plays an important role in anemia management [29]. If the etiology of $\mathrm{Hb}$ variability is not easily discerned, erythropoietic hyporesponsiveness must be envisaged and evaluated, and all efforts brought to reaching stability $[30,31]$.

$\mathrm{Hb}$ testing procedures, practice patterns and reimbursement policies can also contribute to Hb fluctuations. Publications have mentioned center-effects: a retrospective observational study conducted on the US Renal Data System (USRDS) in 2000 and 2001 identified a wide center variation in hematocrit, with a mean difference of 3.06 between the poorest versus the best performing units [32].

All these factors can thus contribute to intra-patient variability. Amongst them, intercurrent events, such as inter-dialysis complications and per-dialysis events have been little studied. De Francisco and colleagues carried out a post-hoc analysis of $\mathrm{Hb}$ concentrations on the pooled records of 5,592 HD patients included in Phase $3 \mathrm{~b}$ trials on the efficacy and safety of darbepoetin alfa for the management of anemia [23]. The intra-patient variability was significantly greater in the presence of infection or inflammation, blood transfusion, or hospitalization including for cardiovascular causes. Little is known about the per-dialysis events which are the most frequent events observed in the HD population: compared to patients treated by peritoneal dialysis, the $\mathrm{Hb}$ level is less stable in patients treated by HD [33] and the requirement of ESAs doses much higher in the HD population [34,35]. Moreover inter dialysis hypotension episodes, which are one of the most frequent events, are known to disturb hemoglobin stability [36], and patients suffering of frequent intradialytic hypotensive episodes present a hemoglobin level lower than that of the stable patients [37].

It has been advised that strategies to minimize $\mathrm{Hb}$ cycling should focus on individualizing targets for the patients. Targets defined by the guidelines are convenient for most patients. However, authors have recommended that the therapeutic decision should center on what $\mathrm{Hb}$ is most appropriate at a "safe ESA dose", even if it means a target of 12 to $13 \mathrm{~g} / \mathrm{dl}$ [38].

In our experience, in order to achieve and stabilize $\mathrm{Hb}$ levels within a safe range, we use moderate DA doses and address the ongoing iron needs of the patients, now injected on the same Q2W basis than DA [39]. Monitoring both $\mathrm{Hb}$ and $\mathrm{DA}$ dosing every other week appears to be the most sensible way to achieve this goal. However, our study is a pilot study, and needs to be confirmed by wider multicenter trials.

\section{Competing interests}

Jacques Rottembourg: No sponsorship or Funding Arrangements during the past five years. Honoraria and reimbursements for lectures from Amgen S.A. S, Fresenius GMH, Vifor LtD.

Floride Kpade: The author declares no competing interest.

Fadia Tebibel: The author declares no competing interest.

Aurélie Dansaert: The author declares no competing interest.

Gaëlle Chenuc : The author declares no competing interest.

\section{Authors' contributions}

JR has contributed to the conception, design, supervision of the study, interpreting the data and wrote the article. FK has contributed to the acquisition of the data. FT has contributed to the acquisition of the data. AD has contributed to the planning of the study in the dialysis unit. GC performed acquisition, analysis and interpretation of data. All authors read and approved the final manuscript.

\section{Acknowledgements}

The authors would like to thank Marie-Danielle Bernard, MD (Anticipsanté Marly le Roi, France), who assisted in writing the manuscript. Her assistance was funded by Amgen S.A.S. (France).

\section{Author details}

'Dialysis Unit, Diaverum Group, Clinique Mont Louis, 11, passage Courtois, 75011, Paris, France. ${ }^{2}$ Cegedim Strategic Data, Boulogne Billancourt, France.

Received: 9 September 2012 Accepted: 28 October 2013

Published: 4 November 2013

\section{References}

1. National Kidney Foundation: NKF-DOQI clinical practice guidelines for the treatment of anemia of chronic renal failure. Am J Kidney Dis 1997 30(Suppl 3):S192-S230

2. National Kidney Foundation: NKF-K/DOQI clinical practice guidelines for anemia of chronic kidney diseases: update 2000. Am J Kidney Dis 2001, 37(Suppl 1):S182-S238.

3. Locatelli F, Aljama P, Barany P, Canaud B, Carrera F, Eckardt KU, Hörl WH, Macdougal IC, Macleod A, Wiecek A, Cameron S: Revised European best practice guidelines for the management of anaemia in patients with chronic renal failure. Nephrol Dial Transplant 2004, 19(Suppl 2):ii1-ii47.

4. KDOQI: Clinical practice guidelines and clinical practice recommendations for anemia in chronic kidney disease. Am J Kidney Dis 2006, 47:S11-S147.

5. KDOQI: Clinical practice guidelines and clinical practice recommendations for anemia in chronic kidney disease - 2007 update of haemoglobin target. Am J Kidney Dis 2007, 50:471-530.

6. KDIGO: Clinical practice guidelines for anemia in chronic kidney disease. Kidney Int Suppl 2012, 2:280-335.

7. Fishbane S, Berns JS: Evidence and implications of haemoglobin cycling in anaemia management. Nephrol Dial Transplant 2007, 22:2129-2132.

8. Berns JS, Elzein H, Lynn Rl, Fishbane S, Meisels IS, Deoreo PB: Hemoglobin variability in epoetin-treated hemodialysis patients. Kidney Int 2003, 64:1514-1521

9. Fishbane S, Berns JS: Hemoglobin cycling in hemodialysis patients treated with recombinant human erythropoietin. Kidney Int 2005, 68:1337-1343. 
10. Ebben JP, Gilbertson DT, Foley RN, Collins AJ: Hemoglobin level variability: associations with comorbidity, intercurrent events, and hospitalisations. Clin J Am Soc Nephrol 2006, 1:1205-1210.

11. Journal Officiel de la République Française. Décret N²006-477 du 26/04/2006, paru au JO du 27/04/2006; 2006. http://www.legifrance.gouv.fr.

12. Singh AK, Szczech $L$, Tang $K L$, for the CHOIR investigators: Correction of anemia with epoetin alfa in chronic kidney disease. N Engl J Med 2006, 355:2085-2098.

13. Besarab A, Bolton WK, Browne JK, Egrie JC, Nissenson AR, Okamoto DM, Schwab SJ, Goodkin DA: The effects of normal as compared with low hematocrit values in patients with cardiac disease who are receiving hemodialysis and epoetin. N Engl J Med 1998, 339:584-590.

14. Kalantar-Zadeh K, Aronoff GR: Hemoglobin variability in anemia of chronic kidney disease. J Am Soc Nephrol 2009, 119:479-487.

15. Eckardt KU, Kim J, Kronenberg F, Aljama P, Anker SD, Canaud B, Molemans B, Stenvinkel P, Schernthaner G, Ireland E, Fouqueray B, Macdougall IC: Hemoglobin variability does not predict mortality in European hemodialysis patients. J Am Soc Nephrol 2010, 21:1765-1775.

16. Steinbrock R: Haemoglobin concentrations in chronic kidney disease. Lancet 2006, 368:2191-2193.

17. Levin A: Understanding recent haemoglobin trials in CKD: methods and lessons from CREATE and CHOIR. Nephrol Dial Transplant 2007, 22:309-312.

18. Locatelli F, Aljama P, Canaud B, Covic A, De Francisco A, Macdougall IC, Wiecek A, Vanholder R: Target haemoglobin to aim for with erythropoiesis -stimulating agents: a position statement by ERBP following publication of the Trial to Reduce Cardiovascular Events with Aranesp ${ }^{\oplus}$ Therapy (TREAT) Study. Nephrol Dial Transplant 2010, 25:2846-2850

19. Verdalles U, Abad S, Vega A, Ruiz Caro C, Ampuero J, Jofre R, Lopez-Gomez $J M$ : Factors related to the absence of anemia in hemodialysis patients. Blood Purif 2011, 32:69-74.

20. Lacson E Jr, Ofsthun N, Lazarus JM: Effect of variability in anemia management on haemoglobin outcomes in ESRD. Am J Kidney Dis 2003, 41:111-124

21. Van der Putten K, van der Baan F, Schellekens H, Gaillard C: Hemoglobin variability in patients with chronic kidney disease in the Netherlands. Int J Artif Organs 2009, 32:787-793.

22. Rottembourg JB, Dansaert A: Strategy feasibility of darbepoetin alfa administration every other week: 2005-2007 experience in a dialysis unit. Nephrol Ther 2011, 7:549-557.

23. De Francisco AL, Macdougall IC, Carrera F, Braun J, Bárány P, Bridges I, Wheeler T, Tran D, Dietrich A: Intercurrent events and comorbid conditions influence hemoglobin level variability in dialysis patients. Clin Nephrol 2009, 71:397-404.

24. Handelman GJ, Levin NW: Red cell survival: relevance and mechanism involved. J Ren Nutr 2010, 20(5 Suppl):S84-88.

25. Walker R, Pussell BA: Fluctuations in haemoglobin levels in haemodialysis, pre-dialysis and peritoneal dialysis patients receiving epoetin alpha or darbepoetin alpha. Nephrol 2009, 14:689-695.

26. Unger EF, Thompson AM, Blank MJ, Temple R: Erythropoiesis-stimulating agents-time for a reevaluation. N Engl J Med 2010, 362:189-192.

27. Roche A, Macdougall IC, Walker RG: Haemoglobin fluctuations in patients on haemodialysis treated with ESAs: clinical observations from two centers. Curr Med Res Opin 2009, 25:2971-2976.

28. Portoles JM, de Francisco ALM, Gorriz JL, Martinez-Castelao A, Lopez-Gomez JM, Arias M, de la Cruz JJ, Cases A, Fernandes E, Aljama P: Maintenance of target hemoglobin level in stable hemodialysis patients constitutes a theoretical task : a historical prospective study. Kidney Int 2008, 74(Suppl 111):S82-S87.

29. Kovesdy CP: Iron and clinical outcomes in dialysis and non-dialysisdependent chronic kidney disease patients. Adv Chronic Kidney Dis 2009 16:109-116.

30. Yee J, Zasuwa G, Frinak S, Besarab A: Hemoglobin variability and hyporesponsiveness: much ado about something or nothing? Adv Chronic Kidney Dis 2009, 16:83-93.

31. Kainz A, Mayer B, Kramar R, Oberbauer R: Association of ESA hypo-responsiveness and haemoglobin variability with mortality in haemodialysis patients. Nephrol Dial Transplant 2010, 25:3701-3706.
32. Fink JC, Hsu VD, Zhan M, Walker LD, Mullins CD, Jones-Burton C, Langenberg P, Seliger SL: Center effects in anemia management of dialysis patients. J Am Soc Nephrol 2007, 18:646-653.

33. Rao R, Ansell D, Gilg JA, Davies SJ, Lamb EJ, Tomson CR: Effect of change in renal replacement therapy modality on laboratory variables: a cohort study from the UK Renal Registry. Nephrol Dial Transplant 2009, 24:2877-2882

34. United States Renal Data System. The concise 2010 annual data report. http://www.usrds.org/archive.aspx

35. Feriani M, De Meester JMJ, McMahon LP, Rottembourg JB, Bridges I, Farouk M, Pronai W: Extended dosing of darbepoetin alfa in peritoneal dialysis patients. BMC Nephrol 2011, 2:13-21.

36. Rouby JJ, Rottembourg J, Durande JP: Hemodynamic changes induced by regular hemodialysis and sequential ultrafiltration hemodialysis: a comparative study. Kidney Int 1980, 17:801-810.

37. Schroeder KL, Sallustio JE, Ross EA: Continuous haematocrit monitoring during intradialytic hypotension: precipitous decline in plasma refill rates. Nephrol Dial Transplant 2004, 19:652-656.

38. Besarab A, Frinak S, Yee J: What is so bad about a hemoglobin level of 12 to $13 \mathrm{~g} / \mathrm{dL}$ for chronic kidney disease patients anyway? Adv Chronic Kidney Dis 2009, 16:131-142.

39. Rottembourg J, Guerin A, Diaconita M: Anemia day: simultaneous, once every two weeks (Q2W) administrations of darbepoetin alfa (DA) and iron (V), improve anemia management in hemodialysis (HD) patients. Philadelphia: Abstract and Poster presented at the Annual Meeting of the American Society of Nephrology; 2011. FR-P01596.

doi:10.1186/1471-2369-14-243

Cite this article as: Rottembourg et al:: Stable hemoglobin in hemodialysis patients: forest for the trees - a 12-week pilot observational study. BMC Nephrology 2013 14:243.

\section{Submit your next manuscript to BioMed Central and take full advantage of:}

- Convenient online submission

- Thorough peer review

- No space constraints or color figure charges

- Immediate publication on acceptance

- Inclusion in PubMed, CAS, Scopus and Google Scholar

- Research which is freely available for redistribution 